\title{
Sala multimídia: Novas tecnologias para potencializar o ensino e a aprendizagem
}

Recebido em 21.12.2012. Aprovado em 28.12.2012 Avaliado pelo sistema double blind review

\author{
Lúcia Maria Gonçalves da Cruz Santos \\ lucinhaacruz@yahoo.com.br \\ Colégio Estadual Dulce Petri - Duque de Caxias -RJ - Brasil.
}

\section{Resumo}

A educação é uma das dimensões essenciais na evolução do ser humano, pois em cada conquista rumo à civilização, faz-se presente junto a esta, a necessidade de transmissão aos semelhantes. Ela é a base do conhecimento para todas as pessoas

Os grandes desafios que os países enfrentam hoje se encontram a melhoria da qualidade do ensino, a permanência dos estudantes na escola e a ampliação do acesso à educação. Tais desafios estão associados ao papel cada vez mais importante que a educação vem assumindo em todo o mundo por sua relevância na busca do desenvolvimento sustentável da sociedade, na construção da cidadania e no combate à exclusão social. A construção de políticas públicas baseadas nessa perspectiva constitui-se estratégia primordial para assegurar a universalização do acesso, a permanência e a aprendizagem em todas as etapas da educação básica. A mudança de ideologia impregnada na sociedade, uma alteração da concepção de ensino e do papel da escola enquanto instituição social. Busca-se uma escola democrática, pluralista, que venha valorizar a diversidade frente às problemáticas sociais perpassadas pelo educador e educando.

No Colégio Estadual Dulce Petri buscamos constantemente melhorar a qualidade do ensino, através de aulas atrativas e projetos multidisciplinares. Um dos fatores que influenciam a aprendizagem é 0 ambiente, 0 espaço onde é realizada a aprendizagem. Pensando nisso, apesar do pouco espaço físico que a Unidade Escolar tem, optamos em transformar um dos espaços e criar a sala multimídia.

Para realização deste projeto o valor solicitado ao edital será de $R \$ 27.439,00$, que será destinado a reforma da sala, material de consumo, compra de mobiliário e de equipamento multimídia e serviços.

$O$ projeto vem de encontro aos anseios de professores e alunos por um espaço diferente e atraente que ajude a motivar a aprendizagem, pois as aulas serão ministradas com equipamentos diferentes aos utilizados nas salas de aula convencionais da Unidade Escolar.

Este projeto vem de encontro ao EDITAL n 2 - Projetos Inovadores em Educação - Fundação Novo Brasil Educação para o Futuro, da qual esperamos o apoio financeiro para implementação deste empreendimento que segue nos próximos capítulos.

Palavras-chaves: Educação. Tecnologias de ensino. Plano de empreendimento. Sala multimídia. 


\section{Contexto da escola}

Colégio Estadual Dulce Petri, escola pública Estadual - Estado do Rio de Janeiro foi fundada em 26 de junho de 1972 e localizada no Parque Beira Mar - Duque de Caxias/ RJ. São 44 professores, 520 alunos, 18 turmas, sendo 09 de Ensino Fundamental ( $6^{\circ}$ ao $9^{\circ}$ ano) e 09 de Ensino Médio Regular e três turnos.
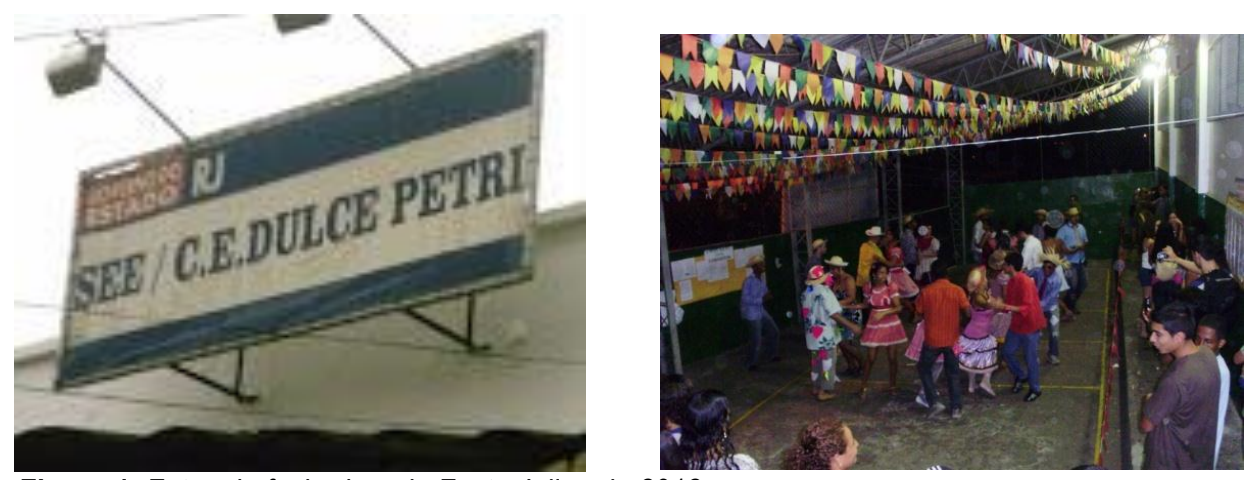

Figura 1: Fotos da fachada e da Festa Julina de 2012.

\section{Que finalidade queremos para a educação? Que papel desejamos para a escola em nossa realidade?}

Queremos ser uma Escola formadora de opinião, consciente de seu papel na formação do caráter dos alunos, colaborando para o desenvolvimento pleno do aluno. Para conquistar nossos objetivos temos as seguintes premissas:

Missão: Preparar cidadãos capazes de enfrentar os desafios futuros com princípios e valores para a formação de uma sociedade justa, conscientes de seus direitos e deveres.

Visão: Ser reconhecida como uma Escola transformadora que tenha um compromisso social e político e busque uma sociedade solidária, justa que estimule o pensamento crítico, a atividade criativa e a cidadania plena.

Valores: Busca por valores éticos, morais e educacionais. Respeito as diferenças e inclusão social.

\section{Breve Histórico da Instituição}

O Colégio Estadual Dulce Petri localiza-se na Rua Florianópolis,no 75- Parque Beira Mar/ Duque de CaxiasRJ. Sendo a única Instituição de Ensino Estadual do Bairro, a procura por vagas é muito grande (principalmente para $06^{\circ}$ ano). A clientela é oriunda das ruas próximas à Escola e da Comunidade Dois Irmãos.

Começou suas atividades em 26 de junho de 1972, pelo Ato de Criação no 15.671- Portaria no 2024/CDCE. Foi transformado em Colégio Estadual pelo Decreto no 9048/86 no Diário Oficial de 08 de julho de 1986. Possui 06 salas de aula, laboratório de informática, sala de professores, sala da Direção, Secretaria, Cozinha, Despensa, Jardim, sala da Orientação Educacional e Pedagógica e pequeno pátio para as atividades desportivas, eventos e recreio dos alunos. Temos 520 alunos, 18 turmas, distribuídos em 03 turnos conforme quadro 1:

\begin{tabular}{|c|c|c|c|c|c|c|c|}
\hline \multicolumn{8}{|c|}{ Turmas e séries do Colégio Estadual Dulce Petri/ 2013} \\
\hline & $6^{\circ}$ ano & $7^{\circ}$ ano & $8^{\circ}$ ano & $9^{\circ}$ ano & $1^{\circ}$ ano & $2^{\circ}$ ano & $3^{\circ}$ ano \\
\hline $1^{0}$ turno & $\mathrm{xxx}$ & $\mathrm{XXX}$ & $\mathrm{xxx}$ & 02 & 02 & 01 & 01 \\
\hline $2^{0}$ turno & 02 & 02 & 02 & $\mathrm{XXX}$ & $\mathrm{xxx}$ & $\mathrm{xXX}$ & $\mathrm{xxX}$ \\
\hline $3^{\circ}$ turno & $\mathrm{xxx}$ & $\mathrm{xxx}$ & $\mathrm{xxX}$ & 01 & 02 & 02 & 01 \\
\hline
\end{tabular}

Quadro 1: Turmas e séries do Colégio Estadual Dulce Petri/ 2013 


\section{Sala multimídia: Novas tecnologias para potencializar o ensino e a aprendizagem}

O quadro administrativo/apoio é composto por 04 merendeiras, 03 serventes, 02 porteiros, 01 coordenador de turno e 01 auxiliar de secretaria.

A Equipe Pedagógica/Administrativa é composta por 01 Diretora Geral, 01 Diretor Adjunto, 01 Secretária, 01 Orientadora Educacional e 01 Coordenadora Pedagógica.

\section{Professores e alunos}

O Corpo Docente é comprometido, consciente de seu papel no processo ensino-aprendizagem e tem sido no processo educativo capaz de assegurar ao aluno o direito de aprender e de se desenvolver de acordo com suas limitações e capacidades, sem perder de vista as possibilidades ofertadas e exigidas pela sociedade contemporânea.

\begin{tabular}{|l|l|}
\hline Disciplina & Número \\
\hline Português & 07 \\
\hline Matemática & 08 \\
\hline Biologia/Ciências & 04 \\
\hline Química & 03 \\
\hline Física & 02 \\
\hline Geografia & 02 \\
\hline História & 03 \\
\hline Filosofia & 03 \\
\hline Sociologia & 02 \\
\hline Educação Física & 05 \\
\hline Artes & 02 \\
\hline Inglês & 03 \\
\hline Total & 44 \\
\hline
\end{tabular}

Quadro 2 - Quantitativo de Professores/2013

O Colégio Estadual Dulce Petri atende 520 alunos nas modalidades de Ensino: $2^{\circ}$ segmento do Ensino Fundamental (EF) e Ensino Médio Regular (EM). Os alunos são distribuídos da seguinte maneira:

\begin{tabular}{|l|l|l|l|l|l|l|l|}
\hline Série/Ano & $\mathbf{6}^{0}$ ano & $\mathbf{7}^{0}$ ano & $\mathbf{8}^{0}$ ano & $\mathbf{9}^{\circ}$ ano & $\mathbf{1}^{0}$ ano & $\mathbf{2}^{0}$ ano & $\mathbf{3}^{0}$ ano \\
\hline Modalidade & EF & EF & EF & EF & EM & EM & EM \\
\hline $\begin{array}{l}\text { Número de } \\
\text { Alunos }\end{array}$ & 60 & 78 & 52 & 92 & 91 & 85 & 62 \\
\hline
\end{tabular}

Quadro 3 - Modalidade de Ensino e quantitativo de alunos do Colégio Estadual Dulce Petri/ 2013

Nosso público é oriundo Comunidade Dois Irmãos (extremamente carente e marcada pela violência) e de ruas próximas à Escola. Temos apenas um aluno com a Síndrome de Crown que requer um tratamento diferenciado, pois o aluno permanece muitas semanas no hospital, sendo necessário que as tarefas e a avaliação dele sejam diferenciadas.

A Escola está inserida no Bairro Parque Beira Mar. É um bairro de classe média-baixa e baixa, localizado a sudeste do município de Duque de Caxias, no Estado do Rio de Janeiro. Fica localizado às margens da Rodovia Washington Luís (BR-040), rodovia essa que o divide da comunidade Beira Mar, e faz limite com os 
bairros Jardim 25 de Agosto, Parque Duque, Miguel Couto, comunidade Vila Operária e o bairro Mineirão. Distante entre 3 e $4 \mathrm{~km}$ do centro de Duque de Caxias e aproximadamente $15 \mathrm{~km}$ do centro do Rio de Janeiro.

O nome do bairro Parque Beira Mar tem sua origem pouco depois do início século XX, quando a região ainda era banhada pela Baía de Guanabara e habitada por pescadores que viviam à sua margem.

As principais atividades econômicas do bairro são as empresas localizadas as margens da BR-040: Centro Empresarial Washington Luís, conjunto de 3 prédios com diversos setores comerciais; o Parque Gráfico da Infoglobo (O Globo, Extra, Expresso) - o maior da América Latina; o Restaurante Rei do Bacalhau, muito conhecido em todo o estado e o mais recente; o Caxias Shopping. Nas ruas próximas à Escola temos: comércio de alimentos, farmácia, bares e papelaria.

O Colégio Estadual Dulce Petri é bem conceituado na região, pelo seu trabalho desenvolvido, tendo um resultado de 3,5 no IDEB. No ano de 2012, alcançamos as metas propostas pela SEEDUC (Secretaria Estadual de Educação) e fomos uma das 313 escolas premiadas com bonificação salarial. Estamos trabalhando para alcançar as metas de 2013 e melhorar nosso resultado no IDEB.

\section{Identificação do problema ou da oportunidade}

"Quando uma criatura humana desperta para um grande sonho e sobre ele lança toda a força de sua alma, todo o universo conspira a seu favor". (Johann Wolfgang Goethe)

As Escolas Públicas tem sido motivadas a resultados cada vez melhores do seu corpo discente e docente. 0 Rio de Janeiro, segundo o IDEB de 2009 ocupava a 26a colocação. No ano de 2011, a SEEDUC- Secretaria Estadual de Educação, lançou para as Escolas Estaduais um Plano de Metas. Neste plano, cada Escola tem uma meta a ser atingida ao logo do ano. Durante os bimestres é feita uma projeção do que deve ser atingido. Para isso, criou-se a GIDE (Gestão Integrada da Escola) com o objetivo de monitorar os resultados, observando os pontos que a Escola pode melhorar. Com as mudanças ocorridas o Rio de Janeiro, atingiu em 2011 a $15^{a}$ colocação no IDEB, subindo 11 posições no ranking nacional. A SEEDUC tem se modernizado e proporcionado mudanças para a melhoria do processo ensino aprendizagem.

Num mundo globalizado e em constante transformação social, econômica, educacional, familiar, etc., as novas tecnologias de informação estão presentes em todos os lugares - do supermercado à produção de alimentos, dos serviços públicos as micro e pequenas empresas, na bomba de combustível, no banco e em toda parte. Esse, por si só já é um bom motivo para que a escola inclua o da tecnologia em sua proposta pedagógica, pois permite que o professor incremente, dê novos ares ao processo ensino-aprendizagem e atraia de maneira mais eficaz o aluno, que, na maioria das vezes, já é usuário e conhecedor dessa tecnologia. Faz-se necessário que a Escola se modernize para poder fazer frente aos inúmeros aparatos disponíveis no mercado, que tanto fascinam e motivam crianças e adultos..Esse crescente avanço acaba convidando os professores a repensarem sua prática, o que é extremamente importante, já que a realidade escolar vem sendo transformada com a presença de novas tecnologias (do mimeógrafo para a copiadora, do projetor de slides para o retroprojetor e atualmente o data show, do quadro negro para o quadro branco, etc).

O Corpo docente do Estado do Rio de Janeiro recebeu laptop com mini modem para acesso à internet (2009) e receberá nos próximos dias tablets com conexão wi-fi para conectar-se a um mundo cada vez mais rápido e ávido por novidades e informações. O uso de tablets no ensino público é outra ação do Proinfo Integrado, programa de formação voltada para o uso didático-pedagógico das Tecnologias da Informação e Comunicação (TIC) no cotidiano escolar, articulado à distribuição dos equipamentos tecnológicos nas escolas e à oferta de conteúdos e recursos multimídia e digitais ${ }^{1}$.

O Programa Nacional de Informática na Educação foi criado pelo Ministério da Educação, através da portaria

\footnotetext{
${ }^{1}$ http://www.fnde.gov.br/programas/programa-nacional-de-tecnologia-educacional-proinfo/proinfo-tablets
} 


\section{Sala multimídia: Novas tecnologias para potencializar o ensino e a aprendizagem}

$\mathrm{n}^{0} 522$ em 09/04/1997, com a finalidade de promover o uso da tecnologia como ferramenta de enriquecimento pedagógico no ensino público fundamental e médio², distribuiu em várias Unidades Escolares a lousa interativa que é um recurso multimídia criado para que os professores tornem as aulas mais dinâmicas e interessantes.

Em termos técnicos, pode-se dizer que ela é uma tela magnética que funciona em total interação com o computador. É composta por um receptor e uma caneta, que devem ser unidos ao projetor Proinfo (projetor que tem a autonomia de um computador).

O conteúdo da aula pode ser projetado e manipulado por meio de canetas especiais, sendo possível escrever na tela e operar qualquer software que esteja em funcionamento. Com isso, o professor pode fazer anotações obre tudo o que estiver sendo projetado, capturar exemplos na Internet, mostrar imagens e vídeos, realizar experimentos simulados e muito mais.

O box ${ }^{3}$ que segue ilustra o uso dessa nova tecnologia no município de Guarujá - SP.

\section{Prefeitura do Guarujá usa salas multimídia Sapienti para dinamizar processos educacionais}

"Rede municipal de ensino conta com 113 ambientes interativos instalados em salas de aula, não em laboratórios; levantamento realizado com alunos da Escola Municipal Francisco Figueiredo mostra que classes que estudam em salas multimídias chegam a saltar de $35 \%$ para $80 \%$ em conceitos satisfatórios; outro benefício dessas novas ferramentas é a diminuição de problemas disciplinares."

\section{Caracterização do produto/serviço elou processo Proposta do projeto}

Analisando as novas necessidades educacionais e tecnológicas e procurando melhorar os índices qualitativos/quantitativos de nossa Unidade Escolar, optamos por criar uma sala multimídia onde reuniremos os recursos tecnológicos que a Escola dispões, objetivando de aumentar os resultados nas avaliações externas e internas.

A tendência é que as aulas sejam mais atrativas e interessantes. Nossa meta é formar pessoas capacitadas a avançar em suas carreiras e em sua própria vida.

O Projeto de criação da SALA MULTIMÍDIA - Espaço para intensificação do saber, atenderá aos alunos do $2^{\circ}$ segmento do Ensino Fundamental e do Ensino Médio do Colégio Estadual Dulce Petri beneficiando 520 estudantes, com faixa etária compreendida entre 10 e 21 anos.

Neste ambiente inovador da aprendizagem estará à disposição do professor para promover aulas interativas e motivadores: cadeiras, telão, aparelhagem de som, TV, DVD, projetor Proinfo, quadro branco, lousa interativa, acesso Wi-fi e acervo de DVD's e CD-Rom's que a Escola possui.

A aprendizagem qualitativa é o foco do projeto, pois não podemos imaginar um aumento quantitativo de resultados sem que a qualidade esteja inerente ao processo. 0 mais importante é que os alunos entendam a importância de aprender e que este processo educativo seja prazeroso.

A importância das novas tecnologias da informação na escola não é só para melhorar o rendimento escolar, é

\footnotetext{
2 http://www.fnde.gov.br/programas/programa-nacional-de-tecnologia-educacional-proinfoRuja-SP

${ }^{3}$ http://www.sapienti.inf.br/novo/prefeitura-do-guaruja-usa-salas-multimidia-sapienti.php
} 
porque elas fazem parte do mundo em que nossos alunos estão inseridos. Só a tecnologia não transforma a educação e cabe aos educadores resgatarem a imagem de pontes para o conhecimento e serem educadores do século XXI, buscando o conhecimento e como difundi-lo.

\section{Apresentação}

$\mathrm{Na}$ primeira etapa do processo haverá uma capacitação para todos os professores (independente da disciplina) através de oficinas promovidas pelo NTE (Núcleo de Tecnologia da Educação - subordinado a SEEDUC), na Unidade Escolar, pois a intenção do projeto é que todos os professores sintam-se motivados a utilizar a sala.

Após a capacitação haverá um agendamento para o uso da sala, para que não haja problema de horários de utilização, pois mesmo a Escola sendo pequena, o número de professores é relativamente grande.

O professor poderá utilizar o material disponível em CD-Rom e DVD, trazer o material a ser utilizado em pendrive ou outra mídia e também poderá acessar a internet e utilizar a vasta gama de material encontrado nos sites de aulas digitais e outros acervos. Trabalhar o conhecimento de forma interdisciplinar, com vistas a possibilitar a compreensão dos fenômenos científicos e sociais em sua totalidade, e não fragmentado e aplicável à realidade presente.

Buscar-se-á criar condições para que os professores não só atuem como transmissores de conteúdos, mas, sobretudo como mediadores da construção de conhecimentos em parceria com os alunos e, por fim, utilizar os recursos tecnológicos disponíveis na escola para tornar o processo de ensino e da aprendizagem mais significativo e prazeroso destacam-se como os resultados alcançados por meio da execução do projeto.

\section{Atividades propostas}

1) jornal impresso e virtual - produção, com a participação dos professores na seleção de temáticas, delimitação dos assuntos, adequação da linguagem, programação visual e gráfica;

2) mapas, tabelas e gráficos demonstrativos - produção, com recursos da informática sobre as pesquisas realizadas;

3) registros fotográficos de aspectos diversos dos contextos explorados;

4) home pages da escola, fotologs e blogs - construção sobre as temáticas estudadas e outros assuntos de interesse dos alunos;

5) texto e poemas - produção de coletânea e de CD de paródias;

6) lista de discussão - criação sobre Física e outros assuntos de interesse;

dos alunos dessa disciplina;

7) composições musicais, cinema e teatro.

\section{Exemplo de uso das novas tecnologias 4}

A Direção da escola busca criar um ambiente propício à busca do conhecimento e à formação - inclusive ética e humanista - de seus alunos. É um lugar onde a aprendizagem constrói-se por intermédio da interação entre alunos e educadores. O aluno é estimulado a conhecer o mundo que o rodeia e a participar, criticamente, da sociedade em que vive. As novas tecnologias educacionais são vistas, dentro do Colégio Eduardo Gomes, como uma ferramenta para atingir esse fim.

\footnotetext{
${ }^{4}$ http://www.sapienti.inf.br/novo/colegio-eduardo-gomes-adota-as-salas-multimidia-sapienti.php
} 


\section{Sala multimídia: Novas tecnologias para potencializar o ensino e a aprendizagem}

\section{Colégio Eduardo Gomes adota salas multimídia Sapienti}

No primeiro trimestre após a implementação, colégio que atende 1720 alunos na região do $A B C D$ paulista conseguiu avançar no conteúdo programático das turmas de Ensino Médio, sobrando tempo para revisões. As novas tecnologias educacionais aumentaram o rendimento escolar e reduziram problemas disciplinares

Empenhada em utilizar, em sala de aula, o que há de mais avançado em tecnologia educacional, Janice está no processo de trocar equipamentos de outra geração por salas multimídia baseadas em lousas digitais. Em janeiro de 2011, a unidade de Ensino Médio inaugurou a ampliação de suas instalações com um novo prédio. Essa unidade conta com 13 salas de aula com infraestrutura de multimídia.

Segundo Janice, a escola já está colhendo os resultados do investimento feito nas novas salas multimídia: aumento do rendimento escolar dos alunos e diminuição de problemas disciplinares. "Conseguimos, também, finalizar o conteúdo programático antes do prazo, o que proporcionou tempo extra para as turmas do Ensino Médio realizarem revisões de conteúdo".

A Sala Multimídia do Colégio Estadual Dulce Petri deve ser exclusivamente utilizada para fins pedagógicos e atividades extra classe, no âmbito das atividades do curso .

A responsabilidade de cuidar da sala será do professor que a estiver utilizando. Os materiais deverão estar em ordem para uma próxima utilização. A manutenção da sala será feita pela Escola, com recursos da verba de manutenção, contudo a utilização dos recursos deverá ser feita de forma consciente para que não hajam despesas desnecessárias. Periodicamente, solicitaremos ao NTE (Núcleo de Tecnologia da Educação), que sejam feitas oficinas para sanar as dificuldades dos professores e dar apoio no uso das novas tecnologias.

\section{Estratégia de implementação}

SWOT é a sigla dos termos ingleses Strengths (Forças), Weaknesses (Fraquezas), Opportunities (Oportunidades) e Threats (Ameaças). A Matriz SWOT é um importante instrumento utilizado para planejamento estratégico que consiste em recolher dados importantes que caracterizam o ambiente interno (forças e fraquezas) e externo (oportunidades e ameaças) de uma Instituição.

A Matriz SWOT é uma ferramenta utilizada para fazer análise ambiental, sendo a base da gestão e do planejamento estratégico numa empresa ou instituição. Graças à sua simplicidade pode ser utilizada para qualquer tipo de análise de cenário. 


\begin{tabular}{|c|c|}
\hline FORÇAS & FRAQUEZAS \\
\hline $\begin{array}{l}\text { - } \\
\text { - } \quad \text { Bom relacionamento entre toda a comunidade } \\
\text { escolar } \\
\text { - } \quad \text { Execução dos planos de cursos } \\
\text { - } \\
\text { - } \text { Ussiduidade dos professores } \\
\text { - } \quad \text { Elização dos recursos tecnológicos e } \\
\text { - }\end{array}$ & $\begin{array}{l}\text { - } \quad \text { Número elevado de alunos aprovados com } \\
\text { Progressão Parcial (Dependência) } \\
\text { - } \quad \text { Equipe pedagógica e administrativa incompleta } \\
\text { - } \quad \text { Baixo desempenho nas avaliações externas } \\
\text { - } \quad \text { Alto índice de alunos em recuperação de } \\
\text { estudos } \\
\text { - } \\
\text { Necessidade de maior participação dos } \\
\text { responsáveis nas reuniões de resultados }\end{array}$ \\
\hline OPORTUNIDADES & AMEAÇAS \\
\hline $\begin{array}{l}\text { - Instituições que oferecem cursos } \\
\text { profissionalizantes: CEI (Centro Educacional } \\
\text { Integrado), SENAC, FUNDEC próximas à } \\
\text { unidade escolar } \\
\text { - Presença de } 3 \text { universidades: UERJ, } \\
\text { Unigranrio e Estácio de Sá } \\
\text { - Oferta de trabalho no comércio local } \\
\text { - Posto de saúde e Hospital próximos à } \\
\text { Unidade Escolar } \\
\text { Estágio no TRT (Tribunal Regional do } \\
\text { Trabalho) }\end{array}$ & $\begin{array}{l}\text { - Atraso dos alunos por causa da demora dos } \\
\text { ônibus } \\
\text { - } \text { Muitos alunos moram em comunidades e } \\
\text { quando ocorre algum conflito, os alunos faltam } \\
\text { às aulas } \\
\text { - Problemas no Sistema Conexão Educação } \\
\text { quanto ao lançamento de notas e na } \\
\text { transferência dos alunos para as turmas e } \\
\text { outras Unidades de Ensino }\end{array}$ \\
\hline
\end{tabular}

Quadro 4 - Matriz SWOT DO C. E. Dulce Petri

\section{Objetivos estratégicos}

Citando Neila Xavier, "o estrategista é aquele que direciona a organização a partir da sua compreensão do ambiente presente e futuro estabelecendo o caminho a ser percorrido para atingimento dos resultados pretendidos".

Nesse sentido, o gestor é o maestro, aquele que deve planejar, orientar e dirigir todos os recursos da organização para um único objetivo, ou seja, coordenar e mobilizar todos os recursos para uma direção especifica e bem determinada.

\begin{tabular}{|c|c|c|}
\hline Objetivos & Metas & Estratégias \\
\hline $\begin{array}{l}\text { Reduzir o número de alunos em } \\
\text { Progressão Parcial (Dependência) e } \\
\text { em Recuperação de Estudos }\end{array}$ & $\begin{array}{l}\text { Diminuir em } 60 \% \text { o número de alunos em } \\
\text { Progressão Parcial. }\end{array}$ & \multirow{2}{*}{$\begin{array}{l}\text { Oportunizar aos alunos atividades } \\
\text { diversificadas } \\
\text { Reforço escolar em todas as disciplinas } \\
\text { sempre que necessário. }\end{array}$} \\
\hline $\begin{array}{l}\text { Reduzir o número de alunos em } \\
\text { Recuperação de Estudos }\end{array}$ & $\begin{array}{l}\text { Reduzir em } 40 \% \text { o número de alunos em } \\
\text { Recuperação de Estudos em até } 24 \\
\text { meses }\end{array}$ & \\
\hline $\begin{array}{l}\text { Aumentar o resultado das avaliações } \\
\text { externas }\end{array}$ & $\begin{array}{l}\text { Elevar o IDEB da Escola de 3,5 para 4,5 } \\
\text { até o ano de } 2015\end{array}$ & $\begin{array}{l}\text { Analisar os resultados do IDEB (de } 2007 \\
\text { até 2011) Direcionar ações e alternativas } \\
\text { para melhorar os resultados }\end{array}$ \\
\hline $\begin{array}{l}\text { Melhorar a Infraestrutura da sala , } \\
\text { transformando o espaço ocioso em } \\
\text { espaço de produção do saber. }\end{array}$ & $\begin{array}{l}\text { Aumentar o número de professores que } \\
\text { realizam aulas diferentes e atraentes }\end{array}$ & $\begin{array}{l}\text { Promover aulas atraentes com o uso de } \\
\text { apostilas, lousa digital, mídias. }\end{array}$ \\
\hline
\end{tabular}

Quadro 5: Objetivos/Metas/ Estratégias 


\section{Sala multimídia: Novas tecnologias para potencializar o ensino e a aprendizagem}

\begin{tabular}{|c|c|c|}
\hline O que vou precisar & Descrição & Como Obter \\
\hline $\begin{array}{l}\text { Reparo na sala que será utilizada. } \\
\text { Compra de mobiliário e } \\
\text { equipamento multimídia. }\end{array}$ & $\begin{array}{l}\text { Conserto no reboco, pintura; } \\
\text { Colocação de uma porta de ferro e grade .troca } \\
\text { de vidros das janelas; } \\
\text { Aquisição de conjuntos estudante.mesa e } \\
\text { cadeira professor } \\
\text { lousa branca; } \\
\text { Projetor Multimídia .Equipamento de Som e } \\
\text { DVD; } \\
\text { Computador e periféricos; } \\
\text { Telão; } \\
\text { Microfone; } \\
\text { TV de LCD de 47'; } \\
\text { Aquisição de programas multimídia; } \\
\text { CDs de músicas, aulas, cursos e palestras, } \\
\text { aparelho de DVD, .máquina fotográfica digital. }\end{array}$ & $\begin{array}{l}\text { Recursos recebidos através do Edital } \\
\mathrm{N}^{0} 2 \text { - Projetos Inovadores em } \\
\text { Educação - Fundação Novo Brasil - } \\
\text { Educação Para o Futuro, verba prevista } \\
\text { para material de consumo e } \\
\text { permanente. }\end{array}$ \\
\hline
\end{tabular}

Quadro 6: Recursos Necessários

\section{Marketing e comunicação}

O marketing é uma função gerencial que oferece estrutura e ferramentas para que as instituições de ensino possam ser melhor sucedidas em atrair e atender seus públicos. Sobretudo, assim como em todo planejamento, conhecer bem o seu público interno e externo, e as necessidades de pesquisas científicas e de formação para o mercado.

São ações que determinam as necessidades e desejos dos estudantes (público-alvo) e que indicam a característica e direcionamento de projetos pedagógicos, comunicação, divulgação e serviços institucionais. É o desafio de ser uma escola de qualidade, e atrativa para os consumidores em todos os níveis de contrato de prestação de um serviço.

O Projeto SALA MULTIMÍDIA: Novas tecnologias para potencializar o ensino e a aprendizagem, será implementado em 2014. Ele terá início com um marketing integrado: Num dos Conselho de Classe ou Grupo de Estudos, do ano de 2013, a equipe gestora do Colégio Estadual Dulce Petri, comunicará sobre necessidade da reforma e organização de uma sala multimídia na Unidade Escolar, onde todos os professores terão a oportunidade de promover uma aula diferente e motivadora, fazendo com que este diferencial seja importante instrumento no processo ensino-aprendizagem.

Para o sucesso do empreendimento, será solicitado o comprometimento e o empenho de todos no projeto. Posteriormente serão feitas reuniões com os responsáveis e alunos, com o objetivo de lhes participar desta nova dinâmica, auxiliando a aprendizagem, que será oferecida a partir de 2014. 


\section{Modelo de negócios}

Abaixo segue a representação do perfil de negócio do projeto:

\begin{tabular}{|c|c|}
\hline $\begin{array}{l}\text { Com quem contamos: } \\
\text { - Docentes } \\
\text { - Gerência Pedagógica. }\end{array}$ & $\begin{array}{l}\text { Atividades: } \\
\text { - Treinamento de professores. } \\
\text { - Curso de capacitação para utilização dos } \\
\text { recursos multimídia } \\
\text { - Aulas interativas. }\end{array}$ \\
\hline $\begin{array}{l}\text { Relacionamento com cliente: } \\
\text { - Reuniões. } \\
\text { - Marketing integrado. }\end{array}$ & $\begin{array}{l}\text { Cliente: } \\
\text { - Alunos do } 2^{\circ} \text { segmento do Ensino Fundamental e } \\
\text { Ensino Médio }\end{array}$ \\
\hline $\begin{array}{l}\text { Espaço: } \\
\text { - } \quad \text { Sala de Aula }\end{array}$ & $\begin{array}{l}\text { Custos: } \\
\begin{aligned} \text { - } & \text { Material permanente. } \\
\text { - } & \text { Material de consumo. } \\
\text { - } & \text { Mão de obra. }\end{aligned}\end{array}$ \\
\hline $\begin{array}{l}\text { Valores: } \\
\text { - } \text { Conteúdo significativo. } \\
\text { - Interesse pelas aulas. } \\
\text { - } \text { Alto percentual de Presença. } \\
\text { - } \text { Melhoria nos resultados das avaliações externas } \\
\text { e internas }\end{array}$ & $\begin{array}{l}\text { Recursos Importantes: } \\
\text { - Equipe. } \\
\text { - Sala de aula equipada. }\end{array}$ \\
\hline \multicolumn{2}{|l|}{ Receitas: } \\
\hline
\end{tabular}

Quadro 7: Organização do Projeto

\section{Organização e gerência do empreendimento}

\section{Equipe gestora:}

O gerenciamento e execução do projeto será realizado por uma equipe gestora capacitada contando com a colaboração de professores conforme apresentado no quadro 8: Administrativo.

\begin{tabular}{|l|l|l|}
\hline Nome & \multicolumn{1}{|c|}{ Função } & \multicolumn{1}{c|}{ Principais Atividades } \\
\hline Lúcia Maria & Diretora & $\begin{array}{l}\text { Responsável pela tomada de preços, orçamentos e } \\
\text { prestação de contas dos recursos destinados a } \\
\text { escola. }\end{array}$ \\
\hline José Francisco & Diretor Adjunto & Planejar, executar e controlar o projeto. \\
\hline
\end{tabular}




\section{Sala multimídia: Novas tecnologias para potencializar o ensino e a aprendizagem}

\begin{tabular}{|l|l|l|}
\hline & & $\begin{array}{l}\text { Elaborar horários. } \\
\text { Marcar reuniões com a equipe escolar. }\end{array}$ \\
\hline Ana Carolina & Coordenadora Pedagógica & $\begin{array}{l}\text { Preparar capacitações dos professores, } \\
\text { acompanhar o cumprimento do currículo e o } \\
\text { trabalho com o equipamento multimídia. }\end{array}$ \\
\hline
\end{tabular}

Quadro 8: Administrativo

\section{Principais Processos}

0 quadro abaixo mostra o perfil da equipe o os processos de trabalho necessários a realização do empreendimento.

\begin{tabular}{|l|l|l|}
\hline Processos & Colaborador & Perfil \\
\hline $\begin{array}{l}\text { Utilização da sala multimídia, para } \\
\text { diferentes atividades nas áreas do } \\
\text { conhecimento. }\end{array}$ & Docentes Concursados & $\begin{array}{l}\text { Conhecimento: Professores concursados, regentes e } \\
\text { envolvidos com o projeto. } \\
\text { Habilidade: Gostam da arte de ensinar, do novo e } \\
\text { das novas tecnologias. } \\
\text { Atitude: Criatividade, responsabilidade e domínio de } \\
\text { turma. }\end{array}$ \\
\hline $\begin{array}{l}\text { Responsabilizar-se pelo controle do } \\
\text { ambiente multimídia, regulando o } \\
\text { horário das turmas/professores. }\end{array}$ & Rúbia Dias & $\begin{array}{l}\text { Conhecimento: Professor concursado, regente a } \\
\text { mais de 15anos. } \\
\text { Habilidades: Informática Educativa. }\end{array}$ \\
\hline $\begin{array}{l}\text { Realizar pesquisas para aquisição } \\
\text { de programas e conteúdos } \\
\text { pedagógicos necessários para a } \\
\text { sala multimídia }\end{array}$ & Solange Lacerda & $\begin{array}{l}\text { Atitude: Criatividade, Responsabilidade e ética. } \\
\text { Conhecimento: Professora Concursada } \\
\text { Habilidades: Domina os processos necessários a } \\
\text { função. } \\
\text { Atitude: Organização, agilidade, responsabilidade e } \\
\text { autonomia. }\end{array}$ \\
\hline $\begin{array}{l}\text { Garantir a limpeza da sala e dos } \\
\text { equipamentos instalados }\end{array}$ & Daniel Fonseca & $\begin{array}{l}\text { Conhecimentos: Concursada para exercer a função } \\
\text { de servente. } \\
\text { Habilidade: Limpeza e conservação. } \\
\text { Atitude: Gosto em organizar e manter o ambiente } \\
\text { limpo e higienizado. }\end{array}$ \\
\hline
\end{tabular}

Quadro 9: Perfil da Equipe de Trabalho 


\section{Plano Financeiro}

Para por em prática o projeto SALA MULTIMÍDIA: Novas tecnologias para potencializar o ensino e a aprendizagem, precisaremos de recursos financeiros. Detalhamos a seguir os elementos necessários para a implementação do projeto.

\begin{tabular}{|c|c|c|c|}
\hline Item & Ano1 & Ano2 & Ano3 \\
\hline Obras e infraestrutura & $\mathbf{4 . 2 8 0 , 0 0}$ & $\mathbf{0 , 0 0}$ & $\mathbf{0 , 0 0}$ \\
\hline Obras & $4.280,00$ & 0,00 & 0,00 \\
\hline Instalações & 0,00 & 0,00 & 0,00 \\
\hline Material Permanente & $\mathbf{8 . 3 2 5 , 0 0}$ & $\mathbf{0 , 0 0}$ & $\mathbf{0 , 0 0}$ \\
\hline Conjunto Escolar Aluno & $3.360,00$ & 0,00 & 0,00 \\
\hline TV 47' LCD & $1.983,00$ & 0,00 & 0,00 \\
\hline Conjunto Professor & 152,00 & 0,00 & 0,00 \\
\hline Maquina Fotográfica & 320,00 & 0,00 & 0,00 \\
\hline Projetor Multimídia & $1.200,00$ & 0,00 & 0,00 \\
\hline Tela de Projeção & 630,00 & 0,00 & 0,00 \\
\hline Home Theater & 680,00 & 0,00 & 0,00 \\
\hline Total & $\mathbf{1 2 . 6 0 5 , 0 0}$ & $\mathbf{0 , 0 0}$ & $\mathbf{0 , 0 0}$ \\
\hline
\end{tabular}

\section{Detalhamento}

Conjunto Escolar Aluno Modelo CJA -06 em ferro tubular e polipropileno 80 unidades.

TV LCD 47" Philips 47PFL3007 Full HD 3 Entradas HDMI 1 USB Entrada para PC

Conjunto Escolar Professor modelo CJP - 01 em ferro tubular, polipropileno e MDA, 01 unidade.

Máquina Fotográfica Digital - Modelo Polaroid IS 827, com cartão de memória de $8 \mathrm{G}$ e bateria de lítio.

Projetor Multimídia BenQ MS502, SVGA (800X600) 2700 Lumens, 3D Ready e 13.000:1 Contraste

Tela de Projeção Eletrônica Retrátil Nardelli de 95p, 100\% em alumínio, pintura com tinta Epóxi de alta resistência na Cor Branca. (padrão), Enrolamento automático por sistema de mola com parada multiponto, Bordas pretas de $5 \mathrm{~cm}$ nas laterais e tarja superior de $30 \mathrm{~cm}$ à $50 \mathrm{~cm}$

> Home Theater 5.1 Samsung 1000W com DVD Player, Conexão HDMI ARC, USB, Função Karaokê, Smart Volume, Power Bass, MP3 - HT -E550K

Obra a ser realizada refere-se à conserto no reboco, pintura, colocação de uma porta de ferro, colocação de porta de grade, troca vidros das janelas. 
Sala multimídia: Novas tecnologias para potencializar o ensino e a aprendizagem

\section{Despesas Correntes}

\begin{tabular}{|c|c|c|c|}
\hline \multicolumn{4}{|c|}{ Projeção das Despesas Correntes } \\
\hline Material de Consumo & Total Ano1 & $\begin{array}{l}\text { Total } \\
\text { Ano2 }\end{array}$ & $\begin{array}{l}\text { Total } \\
\text { Ano3 }\end{array}$ \\
\hline Papel Ofício & $1.260,00$ & $2.862,00$ & $2.369,00$ \\
\hline Toner & $1.420,00$ & $1.200,00$ & $1.959,00$ \\
\hline Caneta Para Quadro Branco & 312,00 & 312,00 & 312,00 \\
\hline $\begin{array}{c}\text { Tinta para Caneta de Quadro } \\
\text { Branco }\end{array}$ & 276,00 & 276,00 & 276,00 \\
\hline Pen Drive & 800,00 & 0,00 & 0,00 \\
\hline Midias & $1.200,00$ & 0,00 & 0,00 \\
\hline Total & $5.268,00$ & $4.650,00$ & $4.916,00$ \\
\hline Passagens e Locomoção & Total Ano1 & $\begin{array}{l}\text { Total } \\
\text { Ano2 }\end{array}$ & $\begin{array}{l}\text { Total } \\
\text { Ano3 }\end{array}$ \\
\hline & 0,00 & 0,00 & 0,00 \\
\hline Total & 0,00 & 0,00 & 0,00 \\
\hline Serviços de Terceiros & Total Ano1 & $\begin{array}{l}\text { Total } \\
\text { Ano2 }\end{array}$ & $\begin{array}{l}\text { Total } \\
\text { Ano3 }\end{array}$ \\
\hline & 0,00 & 0,00 & 0,00 \\
\hline Total & 0,00 & 0,00 & 0,00 \\
\hline Total das Despesas Correntes & $5.268,00$ & $4.650,00$ & $4.916,00$ \\
\hline
\end{tabular}

\section{Detalhamento}

$>$ Papel Ofício - 10 resmas por mês.

$>$ Toner - uma recarga a cada mês.

$>$ Canetas para quadro branco - Uso diário dos professores.

$>$ Tinta para canetas de quadro branco- recargas das canetas quando possível.

> Pen Drive - 01 para cada professor para armazenamento das aulas.

> Mídias - CD's e DVD' pedagógicos e mídias virgens para gravação.

\section{Despesas Administrativas e de Pessoal}

\begin{tabular}{|l|r|r|c|}
\hline \multicolumn{4}{|c|}{ Projeção das Despesas Administrativas e de Pessoal } \\
\hline Administrativas & \multicolumn{1}{|c|}{ Total Ano1 } & Total Ano2 & \multicolumn{1}{c|}{ Total Ano3 } \\
\hline Energia Elétrica & $4.500,00$ & $4.500,00$ & $4.500,00$ \\
\hline Telefone & $1.224,00$ & $1.224,00$ & $1.224,0$ \\
\hline Marketing & $1.560,00$ & $1.560,00$ & $1.560,00$ \\
\hline Total & $7.284,00$ & $7.284,00$ & $7.284,00$ \\
\hline Pessoal & Total Ano1 & Total Ano2 & Total Ano3 \\
\hline Monitor de Informática & $3.600,00$ & $3.600,00$ & $3.600,00$ \\
\hline Total & $3.600,00$ & $3.600,00$ & $3.600,00$ \\
\hline $\begin{array}{l}\text { Total das Despesas Administrativas e de } \\
\text { Pessoal }\end{array}$ & $10.884,00$ & $10.884,00$ & $10.884,00$ \\
\hline
\end{tabular}




\section{Necessidade de Recursos}

\begin{tabular}{|c|c|c|c|c|}
\hline \multicolumn{5}{|c|}{ Cálculo da Necessidade de Recursos } \\
\hline Item & Ano1 & Ano2 & Ano3 & Total \\
\hline I. Total das Despesas Correntes. & $5.268,00$ & $4.650,00$ & $4.916,00$ & $14.834,00$ \\
\hline Material de consumo. & $5.268,00$ & 4650,00 & $4.916,00$ & $14.834,00$ \\
\hline Passagens e Desp. Locomoção. & 0,00 & 0,00 & 0,00 & 0,00 \\
\hline Serviços de Terceiro & 0,00 & 0,00 & 0,00 & 0,00 \\
\hline $\begin{array}{l}\text { II. Total das despesas } \\
\text { Administrativas }\end{array}$ & $7.284,00$ & $7.284,00$ & $7.284,00$ & $21.852,00$ \\
\hline III. Total das Desp. De Pessoal. & $3.600,00$ & $3.600,00$ & $3.600,00$ & $10.800,00$ \\
\hline $\begin{array}{l}\text { IV. Total das Desp. Capital } \\
\text { (investimento). }\end{array}$ & $12.605,00$ & 0,00 & 0,00 & $12.605,00$ \\
\hline $\begin{array}{l}\text { Necessidade de Recursos } \\
(|+||+||+| \mathrm{IV}) \text {. }\end{array}$ & $28.757,00$ & $15.534,00$ & $15.800,00$ & $60.091,00$ \\
\hline Recursos Edital. & $17.873,00$ & $4.650,00$ & $4.916,00$ & $27.439,00$ \\
\hline $\begin{array}{l}\text { Recursos da Organização } \\
\text { (contrapartida). }\end{array}$ & $10.884,00$ & $10.884,00$ & $10.884,00$ & $32.652,00$ \\
\hline
\end{tabular}


Sala multimídia: Novas tecnologias para potencializar o ensino e a aprendizagem

\section{Validações}

\begin{tabular}{|l|l|l|l|}
\hline Itens Financiáveis & Valores Consolidados & $\%$ & Validação \\
\hline Despesas Correntes & $14.834,00$ & $54 \%$ & \\
\hline $\begin{array}{l}\text { Despesas Capital (máximo 50\% do } \\
\text { Projeto) }\end{array}$ & $12.605,00$ & $46 \%$ & \\
\hline Total dos Recursos Solicitados & $27.439,00$ & $100 \%$ & $100.000,00$ \\
\hline
\end{tabular}

\begin{tabular}{|l|c|}
\hline Contrapartida & $32.652,00$ \\
\hline Valor total da contrapartida & $27.439,00$ \\
\hline Valor solicitado ao edital pelo projeto & $119 \%$ \\
\hline Percentual: Recursos solicitados & \\
\hline
\end{tabular}

